\title{
"You want to get on with the rest of your life": a qualitative study of health-related quality of life in gout
}

\author{
Priyanka Chandratre $^{1} \cdot$ Christian D. Mallen $^{1} \cdot$ Edward Roddy $^{1} \cdot$ Jennifer Liddle $^{1} \cdot$ \\ Jane Richardson ${ }^{1}$ (i)
}

Received: 5 June 2015 / Revised: 14 July 2015 / Accepted: 23 July 2015 / Published online: 6 August 2015

(C) The Author(s) 2015. This article is published with open access at Springerlink.com

\begin{abstract}
The objective of the study is to examine the impact of gout and its treatments on health-related quality of life (HRQOL) using focus group interviews. From the baseline phase of a cohort study of HRQOL in gout, 17 participants (15 males, mean age 71 years) with varying attack frequency and treatment with and without allopurinol participated in one of four focus group interviews. All interviews were audiorecorded and transcribed verbatim. Data was analysed thematically. Physical and psychosocial HRQOL in gout was affected by characteristics of acute gout (particularly the unpredictable nature of attacks, location of joint involved in an attack, pain and modifications in lifestyle), lack of understanding of gout by others (association with unhealthy lifestyle, symptoms ridiculed as non-severe and non-serious) as well as participants (not considered a disease) and the lack of information provided by physicians (about causes and pharmacological as well as non-pharmacological treatments of gout). Participants emphasised the impact of acute attacks of gout and prioritised dietary modifications and treatment of acute attacks over longterm urate-lowering therapy. Characteristics of acute gout, lack of understanding and information about gout and its treatments perpetuate poor HRQOL. HRQOL (maintenance of usual diet and reduced frequency of attacks) was associated with urate-lowering treatment. Better patient, public and practitioner education about gout being a chronic condition associated with co-morbidities and poor HRQOL may improve understanding and long-term treatment of gout.
\end{abstract}

Jane Richardson

j.c.richardson@keele.ac.uk

1 Research Institute of Primary Care and Health Sciences, Keele University, Keele, Staffordshire ST5 5BG, UK
Keywords Focus group interviews $\cdot$ Gout $\cdot$ Health-related quality of life · Primary care · Qualitative study · Thematic analysis

\section{Introduction}

Gout is the commonest inflammatory arthritis, affecting $2.5 \%$ of the UK population [1] and causes attacks of acute gouty arthritis, joint damage and chronic pain. It is associated with co-morbidities (obesity, hypertension, diabetes, ischaemic heart disease, chronic kidney disease and treatment with diuretics) $[2,3]$ and socio-demographic features (older age, male gender, ethnicity and lower socio-economic status) [4-6]. Given the complex links between gout, co-morbidities and socio-demographic characteristics, health-related quality of life (HRQOL) in gout is likely to be associated with all these patient characteristics. HRQOL is defined as: "The value assigned to the duration of life as modified by impairments, functional states, perceptions and social opportunities that are influenced by disease, injury, treatment or policy" [7].

To date, qualitative studies of gout have explored HRQOL but have focused on the knowledge and beliefs of patients and providers and perceived barriers to effective treatment rather than on the impact of gout and its treatment on quality of life [8-13]. These studies were conducted using one-to-one interviews with patients $[10,12]$ in mixed primary and secondary care settings [9]. One secondary care-based study used nominal group interviews to assess the impact of gout on HRQOL but focused on the influence of gender and race on HRQOL [8]. To our knowledge, this is the first primary care-based qualitative study to explore patients' perspectives on how gout and its treatments affect HRQOL, using focus group interviews. 


\section{Methods}

Participants for this study were recruited from the baseline phase of a primary care-based cohort study of HRQOL in gout [14]. A sub-sample of 120 baseline responders with a primary care Read code diagnosis of gout or prescription of colchicine or allopurinol in the preceding 2 years were invited to participate in focus group interviews. Drawing on the expertise of the research team, a purposive sampling framework was developed to include participants whose experiences encompassed a range of frequency of attacks over the last 12 months and a proportion taking allopurinol. Since febuxostat is used infrequently in UK primary care, interview participants were not purposively sampled according to febuxostat use.

Non-responders were sent a reminder invitation letter after 2 weeks: Those who did not reply to the reminder letter were not contacted again. Forty-two potential participants who agreed to take part in the interviews were telephoned by the researcher to arrange an interview. Nineteen of these 42 confirmed ability to attend one of the four allocated interview dates. Two did not attend due to unforeseen circumstances, leaving 17 participants. Each of the four focus groups had between three and five participants. Details of the recruitment process are illustrated in Fig. 1.

Prior to commencing the interview, the procedures outlined in the participant information sheet were discussed with each participant. Participants were given the opportunity to ask questions. Written informed consent to take part in the study (including the use of quotations) was obtained from all participants and confirmed at the end of the interview. Three group interviews were held at Keele University and one at a general practice. Ethical approval was gained from the North West Liverpool East Local Research Ethics Committee (REC reference number 12/NW/0297).

Focus groups rely on the interaction between group participants to generate novel ideas and promote discussion around the emerging topics [15]. The moderator (PC) used a topic guide to guide the interview, which had been developed in conjunction with five expert patients with gout from the research centre's Research Users Group. The topic guide was pre-determined but not prescriptive, and participants were encouraged to lead the discussion. The main question of the focus group enquiry was: "What impact has gout and its treatment had on your Quality of Life?" All interviews were audiorecorded and transcribed verbatim.

\section{Thematic analysis}

Thematic analysis was based on Braun and Clarke's framework [16], modified by combining reviewing and defining themes into one stage:

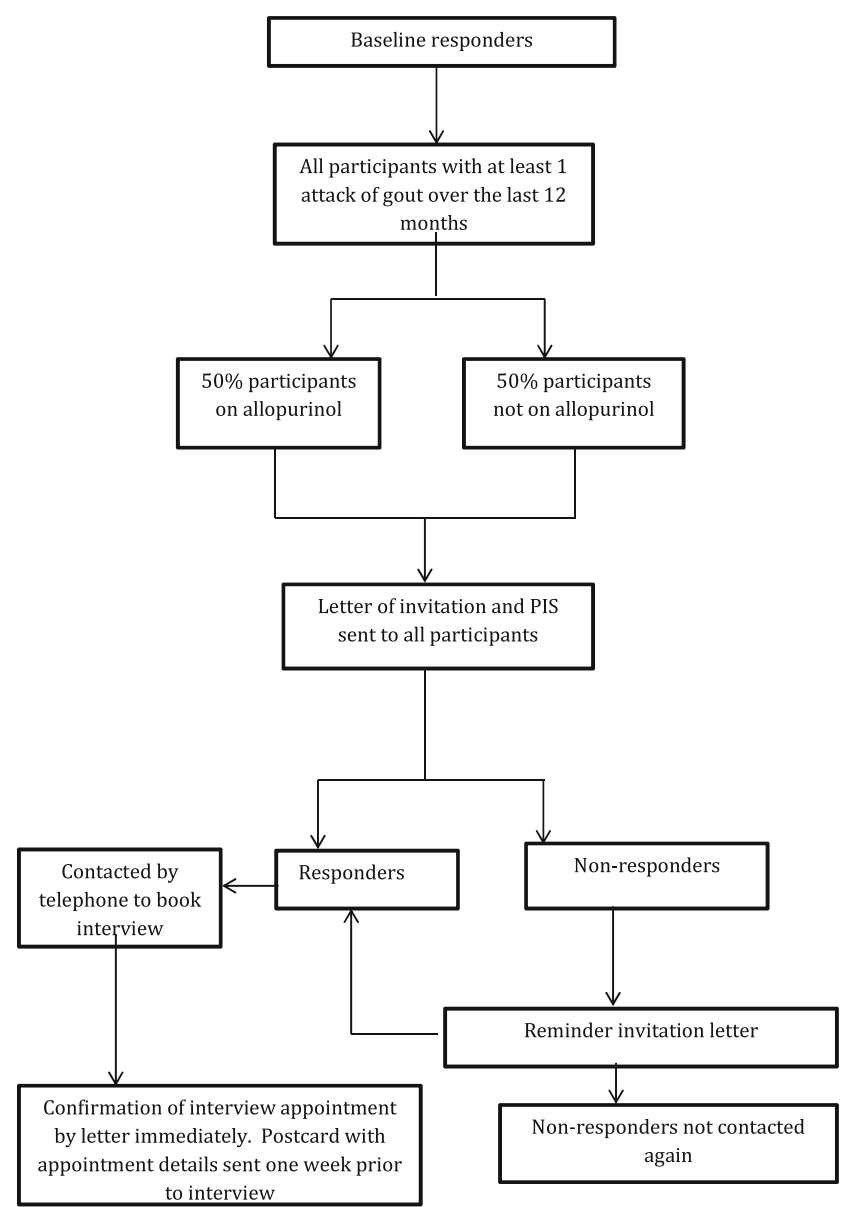

Fig. 1 Recruitment process for the qualitative focus group

I. Familiarisation with the data set

II. Generating and clustering codes together

III. Identification of themes

IV. Review and definition of themes

V. Production of the report

The original transcripts were scrutinised by three researchers (PC, JR, JL) for data relevant to the impact of gout (and its treatments) on all aspects of quality of life, which were then coded. Codes identified by the three researchers were largely similar, and any differences were discussed until a consensus was reached. Codes used to annotate the main text that were similar in nature were clustered together into themes. Similar themes were organised under one overarching theme or higher order descriptive label. Thematic analysis was data driven (inductive) as far as possible; however, previous clinical experience may inevitably have contributed to some degree of deductive analysis. Data analysis and interpretation were iterative as new themes developed on repeated readings of the transcripts, until no new themes could be identified (theoretical saturation) [10]. 


\section{Results}

Seventeen people participated in the interviews (mean age 71 years, 15 males). One participant accompanied another participant with gout (for whom she was a carer) but did not have gout herself. Participant characteristics are presented in Table 1 .

Three overarching themes were developed: characteristics of gout, understanding of gout and beliefs about treatment of gout amongst the participants. The impact of gout on HRQOL is outlined through these themes and sub-themes presented below, illustrated with relevant quotations from the transcripts (Tables 2, 3 and 4).

\section{Characteristics of gout}

\section{The physical and psychological impact of gout attacks}

Participants reported pain affecting multiple sites in the body and varying in intensity (see Table 2). The duration of severe pain could last as long as 3 weeks, but some participants reported a low intensity of pain lasting almost a decade. Desperation to relieve the severe pain of gout was also apparent from some of the extreme self-management techniques). Anticipated worsening of pain upon contact of the affected body part with another person or object in bed reduced comfort and

Table 1 Participant characteristics

\begin{tabular}{lllll}
\hline Gender & $\begin{array}{l}\text { Age } \\
\text { (years) }\end{array}$ & $\begin{array}{l}\text { Interview } \\
\text { location } \\
\text { GP/Keele }\end{array}$ & $\begin{array}{l}\text { Number of } \\
\text { attacks in last } \\
12 \text { months }\end{array}$ & $\begin{array}{l}\text { Taking } \\
\text { allopurinol }\end{array}$ \\
\hline F & 76 & GP & 5 & Yes \\
M & 75 & Keele & 5 & No \\
M & 73 & GP & 2 & No \\
M & 55 & Keele & 3 & Yes \\
M & 67 & Keele & 1 & No \\
M & 68 & Keele & 3 & Yes \\
M & 85 & Keele & 3 & No \\
M & 77 & Keele & 2 & Yes \\
M & 72 & GP & 2 & Yes \\
M & 81 & Keele & 3 & Yes \\
M & 68 & Keele & 2 & Yes \\
M & 64 & Keele & 2 & No \\
M & 64 & Keele & 2 & Yes \\
M & 78 & Keele & 3 & Yes \\
M & 60 & Keele & 4 & No \\
M & 63 & Keele & 3 & Yes \\
M & 75 & Keele & 5 & No \\
F & Unknown & Keele & NA & NA \\
\hline & & & & \\
\hline
\end{tabular}

$M$ male, $F$ female, $G P$ general practitioner, $N A$ not applicable the quality of sleep. Gout was perceived to be more severe if pain was located in larger joints during an attack compared to smaller joints (Table 2) and considered more painful than a fractured bone. Gout caused isolation through reduced mobility arising from pain and swelling in the joints. Being immobile, housebound and unable to do things led to feelings of boredom.

\section{Unpredictable nature of attacks}

The unpredictable onset of acute attacks led to difficulties in planning activities or social engagements in the future, illustrating the direct impact of gout on HRQOL in terms of social opportunities. Some participants were reluctant to make commitments which might not be fulfilled in the event of a sudden attack. Fear of recurrent and unpredictable attacks of gout led one participant to start treatment with allopurinol, which he would not have considered otherwise (Table 2).

\section{Modification of environment and lifestyle}

Symptoms of gout caused hindrance in performing activities of daily living which meant that participants made modifications in their lifestyle, place of living and work environment. Gout not only limited the lifestyles and hence HRQOL of participants affected by it but also of the family member (carer) who reported feeling unhappy or guilty enjoying activities without the person with gout (Table 2).

\section{Understanding of gout}

\section{Over-indulgence as a cause for gout and dietary modifications}

Although some participants considered dietary modifications a key to preventing recurrent attacks (particularly if they thought their previous dietary habits had been 'overindulgent'), others reported uncertainty regarding diet and its role in causing and treating gout. There was a lack of information from 'trusted' sources such as health care practitioners, and participants relied upon both National Health Service (NHS) endorsed and unendorsed websites for detailed dietary information. Self-discovered sources of information were considered to be overwhelming and frightening (Table 3). Participants also reported lack of enjoyment of previously enjoyed activities associated with extremely restricted dietary lifestyles. This aspect of HRQOL is an important one and, at the same time, a confusing one for people with gout.

\section{Gout not a disease}

The stigma associated with stereotypical ideas of gout affecting those who led an unhealthy lifestyle (high consumption of 
Table 2 Participant quotations to illustrate the impact of gout characteristics on HRQOL

\begin{tabular}{|c|c|c|}
\hline Higher order theme & Sub-theme & Quotations within transcripts \\
\hline \multirow[t]{20}{*}{ Gout characteristics } & \multirow[t]{9}{*}{ The impact of gout attacks } & $\begin{array}{l}\text { I mean a toe is relatively innocuous, if you've got it in your knees or hips or something, } \\
\text { then yeah, it's a little more worrying }\end{array}$ \\
\hline & & So I can't really go anywhere or do anything in that sense \\
\hline & & $\begin{array}{l}\text { You're so bored sat there not being able to move your foot, [laughter] that you get } \\
\text { psychological side effects. }\end{array}$ \\
\hline & & I'll get into freezing cold water and sit there. [yeah] I take that pain to take that off \\
\hline & & $\begin{array}{l}\text { You can't turn over, when you're half asleep, you accidently touch something. } \\
\text { You're frightened that she's going to touch it }\end{array}$ \\
\hline & & $\begin{array}{l}\text { But mine lies all over my body, everywhere. From one to another. [right] All down } \\
\text { one side, well everywhere }\end{array}$ \\
\hline & & You really bang your head against the wall \\
\hline & & It gets that painful I'll cry. I can't get rid of it. \\
\hline & & $\begin{array}{l}\text { If it breaks, [yeah] you go to the hospital, put it in plaster, and you're-a bit of a throbbing } \\
\text { and it's gone, but with gout it's bang, bang, bang for days and days }\end{array}$ \\
\hline & \multirow[t]{2}{*}{ Unpredictable nature of attacks } & $\begin{array}{l}\text { The only reason that erm I went back this time to- to see about it was the fact that I was a } \\
\text { little bit frightened if I was going to go on holiday the next day it was going to clobber } \\
\text { me that day }\end{array}$ \\
\hline & & $\begin{array}{l}\text { It's the unpredictability of it, you know, you make a plan to, I don't know, maybe go to } \\
\text { theatre in five weeks' time and when it gets closer you think god, I hope I don't get gout } \\
\text { just the night before }\end{array}$ \\
\hline & \multirow[t]{9}{*}{ Lifestyle modification } & Well I couldn't get my shoe on, last—a week ago since my last one \\
\hline & & When I found out it was gout I changed my lifestyle and stopped drinking \\
\hline & & I have cherries. And I have seeds sometimes, celery seeds \\
\hline & & $\begin{array}{l}\text { Because the damp weather, the cold and damp weather, is just not helping him at all. } \\
\text { And they moved, they sold up and they moved to warmer climates }\end{array}$ \\
\hline & & $\begin{array}{l}\text { I stopped doing these high impact erm exercises, I stopped long distance walking, } \\
\text { because it was painful }\end{array}$ \\
\hline & & Like it's office work now, like you know a desk job now \\
\hline & & Well we can't go out and do the same things \\
\hline & & $\begin{array}{l}\text { I could go out and leave him. [right, yeah] But there's no way I would. [okay] So it does } \\
\text { have an effect on the whole unit }\end{array}$ \\
\hline & & I'm a long distance runner, so when I can't run like I hate it. \\
\hline
\end{tabular}

meat and alcohol) was still widely prevalent in society according to participants. However, some participants did not consider personal actions such as lifestyle choices to be a key cause of gout as they saw it as an illness resulting from a 'natural' accumulation of metabolites in the body rather than a disease. Often, symptoms of gout (joint aches and pains) were attributed by participants to part of a 'normal' ageing process, leading to dismissal of the diagnosis.

\section{Gout considered humorous and only understood by close contacts}

Participants considered gout to be a serious and extremely painful condition and were angered by others not taking it seriously. Participants felt that the rapid onset of symptoms, and others' understanding of it as a non-fatal condition, meant that there was disbelief of the severity of symptoms and the condition. Perceived lower priority for research into gout (compared to other conditions such as drug misuse or dependency which were viewed as self-inflicted) was considered synonymous with the lower severity assigned to it by health care practitioners (Table 3). Awareness and understanding of gout were considered better amongst family and friends who realised the severity of symptoms after being involved in the care or observation of someone who had gout. The perceptions of other people can be seen to have an impact on patients' HRQOL.

\section{Lack of information from health care practitioners}

Lack of information prompted participants to conduct their own internet searches on causes and treatments of gout. They were, however, concerned about the quality and authenticity of information available via these internet sources. Participants felt that health care practitioners assumed that their gout was due to excessive consumption of alcohol (Table 3), 
Table 3 Participant quotations to illustrate the impact of understanding of gout on HRQOL

\begin{tabular}{ll}
\hline Higher order theme & Sub-theme \\
\hline Understanding of gout & $\begin{array}{c}\text { Over-indulgence and dietary } \\
\text { modifications }\end{array}$
\end{tabular}

Gout considered humorous by others and only understood by close family and friends

Lack of information from health care practitioner
Quotations within transcripts

Yeah I know I kind of guess when I might be getting one, [yeah] by the fact that I've over indulged somewhere.

Oh they put everything on there. What am I going to eat? You have to take it with a pinch of salt.

When I looked onto NHS Direct, after I'd got it, that frightens the life out of you if you do anything because you get five pages

It's just a great muddle about when it comes to food

Give them a 12-month diary or something like that. [right] And write each day what they've done that day. [okay] What they've drunk that day. What they've eaten that day. [yeah] And do a research programme like that and maybe you could come up with some facts

For me, disease is something like malaria and erm... But it isn't is it, it's just a build-up of stuff that's naturally in your body

I suppose I was a bit in self-denial, I don't suffer from gout

There's more people than what we think who get it a bit, not coming forward and saying this is a bigger serious problem

In fact I would put it down to aches and pains getting aged really rather than anything

I think there's certain diseases that are quite humorous to - and they're not, but they're humorous to everybody else who hasn't got them

You don't brag about it do you?

Straightaway it's with the well-off people and [that's right, yeah] and the rich food.

It's this thing erm...they don't realise what it is and they just use the old wives' tale, the port and pheasant, rich living

It happens so quick, people just don't believe it.

When you've got gout your partner or friend or whatever, if they see you with gout when it's bad, they suddenly realise how bad it is

I don't think it's perceived to be life threatening, whereas cancer and heart attacks are

They should spend more money on stuff which we ain't brought this on ourselves, [yeah] it's because it's an illness, it's - whatever it is, we've got with us, whereas drugs and - they'll spend money

I found out for myself basically. [okay] So the doctor didn't really explain it that well We've all got ignorance of it. Doctors don't sort of explain exactly what it is

I'd like to know the side effects though, properly [yeah] from a doctor, and not from the internet

No, you go in, you go in, you're the doctor, how much do you drink? I said I don't drink doctor. But as I say it's still treated as a bit of a thing, you know. I think doctors do actually. You know, you've been drinking. How much do you drink?

"I would say my GP almost dismissed my view that [yeah] the attacks were brought on when I stressed the joint, but on the NHS site, definitely it states [yeah] that if you stress a joint it can instigate the gout"

"But you couldn't talk to my doctor about it, he wasn't interested" leading to a reported lack of rapport between health care practitioners and patients.

\section{Beliefs about treatment of gout}

\section{Lack of contact with health care practitioner}

Self-treatment of acute attacks of gout with nonpharmacological methods was reported by participants. Obtaining topical or oral non-steroidal anti-inflammatory drugs (NSAIDs) from the pharmacy was preferred by some participants to presentation to the general pactitioner (GP) for treatment. Some confessed to treating recurrent attacks with left over NSAIDs (obtained originally from a previous consultation). Participants complained of the unavailability of appointments at their GP surgery and the spontaneous resolution of symptoms by the time they were seen. Lack of presentation to the GP for recurrent attacks may lead to lack of opportunity to understand and address the long-term consequences of chronic 
Table 4 Participant quotations to illustrate the impact of treatments on HRQOL

\begin{tabular}{|c|c|c|}
\hline Higher order theme & Sub-theme & Quotations within transcripts \\
\hline \multirow{16}{*}{ Treatment } & \multirow[t]{4}{*}{ Lack of contact with HCP } & $\begin{array}{l}\text { A female participant reported that her general practitioner (GP) was reluctant to refer her to a } \\
\text { specialist even when her gout was sub-optimally controlled }\end{array}$ \\
\hline & & Have a supply if I can feel it coming on, because I've got a spare box at home \\
\hline & & I dropped it down myself to one a day, I don't know what the doctor will say when I tell him \\
\hline & & $\begin{array}{l}\text { So it takes three, like it can take five days to see my doctor. You know, so by the time I get } \\
\text { in there it'll probably have eased down a lot }\end{array}$ \\
\hline & \multirow[t]{5}{*}{$\begin{array}{l}\text { Reluctance to prescribe } \\
\text { and take allopurinol }\end{array}$} & $\begin{array}{l}\text { He says I wouldn't really recommend it if you can get away with it, just come in if you start } \\
\text { getting an attack }\end{array}$ \\
\hline & & I find it quite manageable with anti-inflammatory tablets I take for it \\
\hline & & $\begin{array}{l}\text { I said I'm not being funny here but can I have this one please because this one seems to be } \\
\text { the new one, and much better. She didn't offer it because it's obviously more expensive }\end{array}$ \\
\hline & & I'm old enough now that another tablet for the rest of my life doesn't make a lot of difference \\
\hline & & $\begin{array}{l}\text { I find mine just goes quickly, so I'm tremendously happy, I wouldn't want to be on long term } \\
\text { Allopurinol, not because there's anything wrong with it, or anything, or anything else, } \\
\text { I'm very, very content with what I've got }\end{array}$ \\
\hline & \multirow{4}{*}{$\begin{array}{l}\text { Concerns about side } \\
\text { effects of treatment }\end{array}$} & Because of the other medication that he takes, the gout tablets don't sit well \\
\hline & & $\begin{array}{l}\text { My kidney function, he always checks because I think it's on the border line, so I think that } \\
\text { might have been one of the reasons he was a little bit wary about erm prescribing Allopurinol }\end{array}$ \\
\hline & & And then you go - and then you get gout, it gives you gout. \\
\hline & & $\begin{array}{l}\text { My medic said that Allopurinol can actually cause gout to flare up again. If I had any problems, } \\
\text { any pain, [yeah] to stop taking it immediately. }\end{array}$ \\
\hline & \multirow[t]{3}{*}{ Benefits of treatment } & $\begin{array}{l}\text { You go two for I think it's two months, I've forgotten now, [yes] and then you go to three, } \\
\text { and then that is - that's a miracle }\end{array}$ \\
\hline & & Go to the doctors and get the pills... I wish he'd done it two years ago \\
\hline & & $\begin{array}{l}\text { "Well I'm still eating mussels and king prawns and everything like that. The Allopurinol } \\
\text { I suppose is to let you do that isn't it?" }\end{array}$ \\
\hline
\end{tabular}

progressive gout and its associated co-morbidities on HRQOL for the patient.

\section{Reluctance to prescribe and take allopurinol}

A recurrent theme in the interviews was that lifelong uratelowering therapy (ULT) treatment with allopurinol was not widely advocated by health care practitioners if the patients had single or infrequent attacks or in the presence of coexisting renal impairment. Instead, treatment of acute attacks only with NSAIDs was often reportedly advised by health care practitioners, as well as being the preferred approach for some participants (see Table 4). Those who had mild symptoms were content without any treatment at all or quick resolution of symptoms with NSAIDs. Reluctance to take lifelong treatment (allopurinol) was expressed by a few participants despite having no particular concerns regarding allopurinol. These participants may consider taking lifelong medication a burden. Some participants reported being less concerned about taking allopurinol for the remainder of their lives as they grew older (Table 4). Not taking treatment can have a negative effect on HRQOL.

\section{Concerns about side effects of treatment}

Lack of information about the possibility of an acute attack due to allopurinol initiation or titration caused concerns for some participants. Other participants were informed of this possibility but were incorrectly advised to discontinue treatment with allopurinol should an acute attack occur. Some participants (including the carer) were worried about interaction between allopurinol and other medications taken for co-morbid conditions. Treatment of gout with allopurinol was considerably harder in the presence of other co-morbid conditions such as renal disease, according to some participants.

\section{Perceived benefits of treatment}

Some participants wished for earlier treatment with allopurinol once they realised that treatment could reduce the frequency of attacks (Table 4). Treatment with allopurinol was perceived to improve HRQOL by reducing the frequency of recurrent attacks. 


\section{Discussion}

The impact of gout and its treatments on broad physical, social functioning and mental health [17] components of HRQOL was represented through three higher order themes: gout characteristics, understanding of gout and treatments for gout. The effect on physical HRQOL was evident through its characteristic symptoms of pain and swelling in the affected joint, leading to reduced mobility and potential adverse effect on psychological HRQOL. Social HRQOL may be affected by the unpredictable nature of attacks and modifications in lifestyle. Participants' treatment preferences and lack of knowledge about the benefits of ULT may contribute towards poor HRQOL in gout.

The impact of gout symptoms on physical functioning and psychological HRQOL $[8,10]$, work absence and productivity has been described previously [18]. Under-reporting of gout due to reluctance in accepting the diagnosis (stigma attached with the stereotypical phenotype of those who get gout) and stoicism due to societal perceptions (non-serious) have also been found previously [10]. Non-presentation to a health care practitioner for treatment of further attacks prevents the opportunity to discuss the association of gout with permanent joint damage, disability and co-morbidities [19] and may lead to poor HRQOL, which can be addressed through treatment with a urate-lowering agent such as allopurinol. A previous observational cohort study has shown statistically and clinically meaningful improvement in HRQOL (through reduction in serum uric acid (SUA) and the frequency of attacks) in participants with chronic gout treated with ULT [ 20]. Participants in our study highlighted lack of awareness of the need for lifelong ULT, concerns about side effects, induction of acute attacks with ULT, concerns regarding polypharmacy causing adverse drug interactions and perception that treatment is only needed for acute attacks as reasons for not taking ULT, which have been common to other qualitative studies using semi-structured or nominal group interviews $[9,12,13]$. Such beliefs may contribute towards underutilisation of ULT in primary care [21]. Leaving recurrent attacks untreated may lead to progressive gout which has been previously associated with negative experiences [10]. Comorbidities such as renal impairment have been independently associated with poor HRQOL [22]. Better psychological HRQOL (measured by the Short Form 36 scale) in adults $>70$ years of age with treatment failure gout compared to younger subjects and general population has been seen previously [23].

One important concept identified in this study is the distinction between gout as an illness (social meaning of the condition) rather than a disease (a biological condition) [24]. This belief may be rooted within social constructionism (illnesses are socially constructed at an experiential level which is based upon the individual's understanding of the disease and perceptions of his or her identity post diagnosis) [25]. Another addition to the findings of existing studies is that participants in this study considered the unpredictable nature of attacks and location of joint pain and swelling to be of utmost importance in affecting their HRQOL. These findings may explain how previously noted features of quantitative studies [26, 27] such as attack frequency and number of joints involved during an attack affect HRQOL. Although well-recognised as features of gout by health care practitioners, associated comorbidities [28] and tophi were noticeably not discussed amongst participants of this study, which may imply that they did not consider these to affect HRQOL. Although some participants acknowledged that treatment of gout was difficult in the context of co-morbidities such as renal diseases, none attributed co-morbid conditions as a risk factor for hyperuricaemia and gout. Untreated co-morbid conditions in gout may impair HRQOL independent of gout factors [22]. Tophi have also been associated with poor HRQOL (measured by generic questionnaires) in other studies [27, 29]. This may be due to the fact that tophi are less common in primary care, where our sample was taken from, compared to secondary care, where much previous research has been conducted.

Other findings of our study supported by existing literature include the desire for greater health care practitioner-led information [9] and the emphasis on diet as a key causative factor in development of gout $[13,30]$. However, whereas participants in our study were keen on modifying their lifestyle to prevent recurrent attacks, participants in the other study [30] did not perceive gout to be influenced by their personal actions. Such differences in findings may be attributed to the sampling frame (participants with disease duration $<10$ years), geographical location (New Zealand) and study design (cohort study conducted using the Brief Illness Perception Questionnaire).

\section{Strengths of the study}

To our knowledge, this is the first focus group study to evaluate the effects of gout and its treatment on HRQOL. Focus group interaction between participants may have contributed towards uninhibited discussion [31]. Group interaction also promoted exchange of ideas, anecdotes and information, which may have led to novel themes that would not have developed in a one-to-one setting. Such themes add depth to our understanding of the impact of gout. Although initially designed to study the impact of gout and its treatment on HRQOL, the group interactions went beyond these realms and introduced discussions about beliefs and knowledge of gout, both of which link into the impact on HRQOL. The patient sample was broadly representative of the experience of the primary care population with gout in the UK as it covered a range of attack frequencies and just over half of the participants were on ULT (allopurinol). Participation of a carer 
for someone with gout added a first-hand perspective of the impact of gout on family and friends. Independent reviews of the transcripts by three researchers added robustness to the identification of the codes, ensuring that they reflected participants' views as closely as possible.

\section{Limitations of the study}

Limitations of this study include a sample consisting of exclusively Caucasian and mostly male participants, reducing the applicability of the findings beyond these ethnic and gender groups. However, data from qualitative research is useful in enhancing understanding of the social phenomenon through volume, depth and complexity [31]. Previous qualitative studies have examined the impact of gender and race on HRQOL in people with gout but have not explored the influence of age $[8,13]$. Owing to the study design and sample, we were unable to examine this aspect of HRQOL in gout which should be the focus of future research studies. Although largely present in a passive role, the presence of a moderator and research assistant may have influenced the participant responses.

\section{Implications for clinical practice and further research}

From the participants' perspective, HRQOL is very much influenced by the acute symptoms and 'unpredictable' nature of gout. However, patients need to be made aware of the irreversible joint damage (regardless of joint location and size) associated with untreated chronic gout [32] which may lead to chronic poor HRQOL over time. At present, there appears to be patient preference for short-term symptomatic treatment of gout over ULT. Health care practitioners need to be aware and be able to explain to patients that ULT is necessary to see a long-term reduction in SUA thereby reducing the frequency of attacks, shrinkage and dissolution of tophi [33], leading to an improvement in HRQOL long term [20]. As well as the possibility of onset of an acute attack of gout, they should be advised about its management and the need to continue allopurinol through the duration of the acute attack.

Patients also need to be made aware by health care physicians that gout is a recognised independent risk factor for comorbidities [34-36] which should be screened for and treated alongside gout as they are known to be independently associated with poor HRQOL [22]. Greater awareness of gout in the context of co-morbidities and genetic susceptibility [37] may steer away from the historical association of gout with excessive intake of alcohol and food $[2,32]$. Greater information on the role of diet and exercise from health care practitioners could also promote lifestyle modification and patient engagement in management of the condition.

The influence of gender (females) and cultural perceptions or beliefs (different ethnicities) on HRQOL could also be explored through further qualitative studies. Although lack of information from clinicians was a recurrent theme, this was the participants' perception and it may be useful to explore clinicians' perspective on this issue as well as their perceptions of what affects HRQOL in gout.

\section{Key messages}

- HRQOL was impaired due to gout characteristics, lack of understanding and information about gout.

- Patients expressed a general preference for treatment of acute attacks of gout over lifelong ULT.

- Better patient (and physician) education is warranted to address these factors which perpetuate poor HRQOL.

Acknowledgments The authors would like to thank the administrative and health informatics staff at Keele University's Arthritis Research UK Primary Care Centre, staff and patients of the participating practices.

Financial support $\mathrm{PC}$ is funded by the National Institute for Health Research (NIHR) School for Primary Care Research. CDM is funded by the National Institute for Health Research (NIHR) Collaborations for Leadership in Applied Health Research and Care West Midlands, the NIHR School for Primary Care Research and a NIHR Research Professorship in General Practice (NIHR-RP-2014-04-026). The views expressed are those of the author(s) and not necessarily those of the NHS, the NIHR or the Department of Health. The study funders had no role in the study design; data collection, analysis or interpretation; in the writing of the paper or in the decision to submit the paper for publication.

\section{Disclosures None.}

Open Access This article is distributed under the terms of the Creative Commons Attribution 4.0 International License (http:// creativecommons.org/licenses/by/4.0/), which permits unrestricted use, distribution, and reproduction in any medium, provided you give appropriate credit to the original author(s) and the source, provide a link to the Creative Commons license, and indicate if changes were made.

\section{References}

1. Kuo C, Doherty M, Grainge MJ, Zhang W (2013) Geographic Variations Of Gout Epidemiology In The United Kingdom: A Nationwide Population Study: 1993[Abstract]. Arthritis Rheum 65(Supplement 10):S850

2. Doherty M, Jansen TL, Nuki G, Pascual E, Perez-Ruiz F, Punzi L, So AK, Bardin T (2012) Gout: why is this curable disease so seldom cured? Ann Rheum Dis 71(11):1765-70

3. Choi HK, Ford ES, Li C, Curhan G (2007) Prevalence of the metabolic syndrome in patients with gout: The Third National Health and Nutrition Examination Survey. Arthritis Care Res 57(1):10915

4. Roddy E, Zhang W, Doherty M (2007) Is gout associated with reduced quality of life? A case-control study. Rheumatology 46(9):1441-4

5. Hayward RA, Rathod T, Roddy E, Muller S, Hider SL, Mallen CD (2013) The association of gout with socioeconomic status in primary care: a cross-sectional observational study. Rheumatology 52(11):2004-8

6. Taylor W, Smeets L, Hall J, McPherson K (2004) The burden of rheumatic disorders in general practice: consultation rates for 
rheumatic disease and the relationship to age, ethnicity, and smallarea deprivation. N Z Med J 117(1203):U1098

7. Patrick DL, Erickson P (1993) Health status and health policy: quality of life in health care evaluation and resource allocation. Oxford University Press, Oxford

8. Singh JA (2014) The impact of gout on patient's lives: a study of African-American and Caucasian men and women with gout. Arthritis Res Ther 16(3):R132

9. Harrold LR, Mazor KM, Velten S, Ockene IS, Yood RA (2010) Patients and providers view gout differently: a qualitative study. Chronic Illness 6(4):263-71

10. Lindsay K, Gow P, Vanderpyl J, Logo P, Dalbeth N (2011) The experience and impact of living with gout: a study of men with chronic gout using a qualitative grounded theory approach. J Clin Rheumatol 17(1):1-6

11. Harrold LR, Mazor KM, Peterson D, Firneno C, Yood RA. Patient knowledge and beliefs concerning gout and its treatment. Arthritis Rheum. 2010;62

12. Spencer K, Carr A, Doherty M (2012) Patient and provider barriers to effective management of gout in general practice: a qualitative study. Ann Rheum Dis 71(9): 1490-5

13. Singh JA (2014) Challenges faced by patients in gout treatment: a qualitative study. J Clin Rheumatol 20(3):172-4

14. Chandratre P, Mallen C, Richardson J, Rome K, Bailey J, Gill R, Hider S, Mason J, Mayson Z, Muller S, Purcell C, Titley J, Wathall S, Zwierska I, Roddy E (2012) Prospective observational cohort study of Health Related Quality of Life (HRQOL), chronic foot problems and their determinants in gout: a research protocol. BMC Musculoskelet Disord 13(1):219

15. Barbour R. Doing focus groups. Sage Publications Limited; 2008

16. Braun V, Clarke V (2006) Using thematic analysis in psychology. Qual Res Psychol 3(2):77-101

17. Hirsch JD, Lee SJ, Terkeltaub R, Khanna D, Singh J, Sarkin A, Harvey J, Kavanaugh A (2008) Evaluation of an instrument assessing influence of gout on health-related quality of life. J Rheumatol 35(12):2406-14

18. Kleinman NL, Brook RA, Patel PA, Melkonian AK, Brizee TJ, Smeeding JE, Joseph-Ridge N (2007) The impact of gout on work absence and productivity. Value Health 10(4):231-7

19. Chandratre P, Roddy E, Mallen C (2012) Patient related factors are also important in treating gout. BMJ 344:e191

20. Khanna PP, Perez-Ruiz F, Maranian P, Khanna D (2011) Long-term therapy for chronic gout results in clinically important improvements in the health-related quality of life: Short form-36 is responsive to change in chronic gout. Rheumatology 50(4):740-745, Arte Number: keq346. ate of Pubaton: Ar 2011

21. Kuo C, Grainge MJ, Mallen C, Zhang W, Doherty M. Rising burden of gout in the UK but continuing suboptimal management: a nationwide population study. Annals of the Rheumatic Diseases. 2014 January 15

22. Singh JA, Strand V (2008) Gout is associated with more comorbidities, poorer health-related quality of life and higher healthcare utilisation in US veterans. Ann Rheum Dis 67(9):1310-6
23. Becker MA, Schumacher HR, Benjamin KL, Gorevic P, Greenwald M, Fessel J (2009) Quality of life and disability in patients with treatment-failure gout. J Rheumatol 36(5):1041-8

24. Eisenberg L (1977) Disease and illness distinctions between professional and popular ideas of sickness. Cult Med Psychiatry 1(1): 9-23

25. Conrad P, Barker KK (2010) The social construction of illness: key insights and policy implications. J Health Soc Behav 51(1 suppl): S67-79

26. Lee SJ, Hirsch JD, Terkeltaub R, Khanna D, Singh JA, Sarkin A, Kavanaugh A (2009) Perceptions of disease and health-related quality of life among patients with gout. Rheumatology 48(5): $582-6$

27. Khanna PP, Nuki G, Bardin T, Tausche AK, Forsythe A, Goren A, Vietri J, Khanna D (2012) Tophi and frequent gout flares are associated with impairments to quality of life, productivity, and increased healthcare resource use: results from a cross-sectional survey. Health Qual Life Outcomes 10:117

28. Roddy E, Doherty M (2010) Epidemiology of gout. Arthritis Res Ther 12:223

29. Alvarez-Nemegyei J, Cen-Piste JC, Medina-Escobedo M, Villanueva-Jorge S (2005) Factors associated with musculoskeletal disability and chronic renal failure in clinically diagnosed primary gout. J Rheumatol 32(10):1923-7

30. Dalbeth N, Petrie KJ, House M, Chong J, Leung W, Chegudi R, Horne A, Gamble G, McQueen FM, Taylor WJ (2011) Illness perceptions in patients with gout and the relationship with progression of musculoskeletal disability. Arthritis Care Res 63(11):1605-12

31. Bowling A. Research methods in health. Open University Press Maidenhead; 2009

32. Spencer KT, Carr A, Doherty M. Patient-related barriers to the effective management and treatment of gout. Rheumatology.Conference: Rheumatology 2011 Brighton United Kingdom.Conference Start: 20110412 Conference End: 20110414.Conference Publication: (var.pagings). 2011 April 2011;50:84-5.

33. Perez-Ruiz F (2009) Treating to target: a strategy to cure gout. Rheumatology 48 Suppl 2:ii9-ii14

34. Roddy E, Mallen CD, Doherty M. BMJ. 2013 BMJ Publishing Group Ltd;347.

35. Edwards NL (2008) Treatment-failure gout: a moving target. Arthritis Rheum 58(9):2587-90

36. Gaffo AL, Edwards NL, Saag KG (2009) Hyperuricemia and cardiovascular disease: how strong is the evidence for a causal link? Arthritis Res Ther 11(4):240

37. Kolz M, Johnson T, Sanna S, Teumer A, Vitart V, Perola M, Mangino M, Albrecht E, Wallace C, Farrall M, Johansson A, Nyholt DR, Aulchenko Y, Beckmann JS, Bergmann S, Bochud M, Brown M, Campbell H, EUROSPAN Consortium, Connell J, Dominiczak A, Homuth G, Lamina C, McCarthy MI, ENGAGE Consortium, Meitinger T, Mooser V, Munroe P, Nauck M, Peden J et al (2009) Meta-analysis of 28,141 individuals identifies common variants within five new loci that influence uric acid concentrations. PLoS genetics 5(6):e1000504 